\title{
SISTEM KENDALI METODE PID DAN KOMBINASI SPESIFIKASI PADA KECEPATAN TINGGI INDUKSI MOTOR
}

\author{
Pohny \\ Teknik Informatika, Fakultas Ilmu Komputer dan Teknologi Informasi, Universitas Mulawarman \\ J1. Barong Tongkok No. 6 Kampus Gn. Kelua, B29, 75127 \\ E-Mail : : pohny28@gmail.com
}

\begin{abstract}
ABSTRAK
Metode desain kendali menggunakan konveksitas dari umum loop tertutup spesifikasi kinerja. Sehubungan dengan loop tertutup fungsi transfer sistem untuk menggabungkan memenuhi setidaknya satu loop tertutup spesifikasi kinerja dengan merumuskan pengendali tunggal yang memenuhi semua spesifikasi. Sedangkan kendali gain tuning pusat proses desain, proses tuning sangat disederhanakan, jika dibandingkan disajikan ketika satu set kendali keuntungan disesuaikan untuk memenuhi kombinasi simultan spesifikasi loop tertutup. Metode kendali metode ini yang diusulkan diterapkan pada motor AC induksi kecepatan tinggi, dengan inner-loop flux vector pengendali diterapkan, untuk merancang kendali posisi sistem.
\end{abstract}

Kata kunci: Motor AC induksi, PID,Kombinasi spesifikasi,Kecepatan Tinggi

\section{PENDAHULUAN}

Saat ini Proporsional, Integral, dan Derivatif (PID) struktur kendali yang paling umum digunakan di industri, terutama karena fakta bahwa itu relatif mudah untuk merancang dan mengimplementasikan.

Namun, seperti spesifikasi kinerja menjadi lebih ketat, yaitu kinerja yang lebih tinggi, tugas kelebihan tuning menjadi semakin sulit karena fakta bahwa beberapa spesifikasi yang bersamaan biasanya bertentangan satu sama lain. Oleh karena itu, ada kebutuhan untuk metode desain kendali yang handal untuk secara sistematis mendesain kendali loop tertutup untuk memenuhi semua spesifikasi secara bersamaan[13].Bagaimana mengembangkan untuk kendali posisi dari kecepatan tinggi motor $\mathrm{AC}$ induksi untuk menguji pengendali dan mengembangkan model simulasi motor AC [1].

Sebuah motor pada dasarnya terdiri dari dua bagian. Stator dan rotor, internal struktur motor AC induksi digambarkan pada gambar 1. Stator adalah bagian stasioner yang menetapkan medan magnet. Stator adalah magnet permanen jenis motor DC atau sekumpulan gulungan kawat motor AC induksi[2].

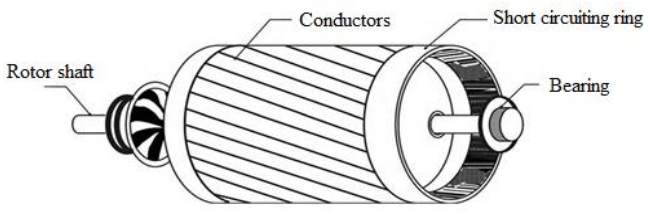

Gambar 1: Struktur internal Squirrel-cage Jenis AC Motor Induksi

Rotor adalah bagian yang berputar memegang poros bahwa pasangan beban mekanik. Sebuah rotor khas dari jenis squirrel-cage yang ditemukan di motor AC induksi memiliki aluminium terhubung ke cincin yang pendek berakhir bersama-sama[3]. Motor AC induksi dijelaskan oleh persamaan dinamis nonlinear, yang dapat dinyatakan sebagai persamaan diferensial yang mewakili kedua sistem listrik dinamis dan dinamika sistem mekanik[5]. Perilaku dinamis dari motor induksi tiga fase yang seimbang dalam model elektro mekanik terdiri dari lima persamaan diferensial biasa diberikan di bawah, dinyatakan dalam stator tetap koordinat.

Model ini mencakup persamaan mekanik serta hubungan listrik. Perhatikan bahwa pilihan keadaan untuk model keadaan-ruang tidak unik. Untuk kenyamanan manipulasi masa depan persamaan, kita telah memilih saat stator dan fluks rotor, $I_{d s}, I_{q s}, \psi_{d r}$ dan $\psi_{q r}$ sebagai variable[4]. Karena fluks rotor, $\psi_{d r}$ dan $\psi_{q r}$, dapat direpresentasikan sebagai:

dimana konstanta positif $L_{1^{\prime}} K_{1}, a_{1}, a_{2}, a_{3}$ dan $R_{1}$ diberikan di bawah ini:

$$
\begin{gathered}
a_{1}=\frac{M_{e} R_{r}}{L_{r}^{2}}, a_{2}=\frac{n_{p} M_{e}}{L_{r}} \quad a_{3}=n_{p} L_{r}, \\
K_{1}=R_{r} M_{e} \\
L_{1}=L_{s}-\frac{M_{e}^{2}}{L_{r}}, R_{1}=\frac{\left.M_{e}^{2} R_{r}-L_{r}^{2} R_{s}\right)}{L_{r}^{2}}
\end{gathered}
$$

dimana $: n_{p}=$ Jumlah kutup pasang dari motor

$$
\begin{aligned}
& I_{d s}, I_{q s}=\text { berubah saat stator di kerangka } \\
& \text { acuan stator-tetap } \\
& I_{d r}, I_{\text {qr }}=\text { diubah arus rotor di kerangka } \\
& \text { acuan stator-tetap } \\
& V_{d,}, V_{q}=\text { diubah tegangan stator di } \\
& \text { kerangka acuan stator-tetap } \\
& \ddot{\Theta}=\text { rotor sudut percepatan }\left(\mathrm{rad} / \mathrm{sec}^{2}\right) \\
& \theta=\text { rotor kecepatan sudut ( } \mathrm{rad} / \mathrm{sec}) \\
& R_{r}=\text { resistensi rotor dari motor } \\
& R_{s}=\text { resistensi stator motor } \\
& L_{r}=\text { rotor induktansi motor } \\
& L_{s}=\text { stator induktansi motor } \\
& M_{e}=\text { mutual induktansi motor } \\
& \mathrm{J}=\text { momen inersia rotor dan beban }(\mathrm{kg} \text { - } \\
& \mathrm{m}^{2} \text { ) }
\end{aligned}
$$


$\mathrm{B}=$ koefesien redaman $\left(\mathrm{kg}-\mathrm{m}^{2} / \mathrm{sec}\right)$

$$
a_{0}=M_{e}^{2}-L_{r} L_{s}
$$

Penelitian ini menggunakan pendekatan metode desain kendali beberapa spesifikasi secara bersamaan.Membahas dua teori kendali yaitu PID konvesional dan beberapa spesifikasi secara bersamaan[6]. Metode kendali beberapa spesifikasi secara bersamaan digunakan untuk menstabilkan kendali motor AC induksi dan untuk mencapai keseluruhan spesifikasi kinerja[7].

Batasan masalah penelitian ini menggunakan pendekatan metode desain kendali beberapa spesifikasi secara bersamaan.Membahas dua teori kendali yaitu PID konvesional dan beberapa spesifikasi secara bersamaan.Metode kendali beberapa spesifikasi secara bersamaan digunakan untuk menstabilkan kendali motor $\mathrm{AC}$ induksi dan untuk mencapai keseluruhan spesifikasi kinerja.

Tujuan penelitian melaksanakan jenis hukum kendali, seperti PID atau kendali gabungan spesifikasi secara bersamaan.Mengembangkan simulasi program dari motor AC induksi menggunakan perangkat lunak komersial matlab /simulink.

\section{BAHAN DAN METODE}

Model dinamis dari motor AC induksi dikembangkan dalam penelitian ini. Dengan model dinamik ini, kami menerapkan teori kendali yang tepat untuk mengembangkan pengendali untuk motor AC.

Jenis penelitian ini adalah simulasi untuk mengembangkan kendali posisi dari kecepatan tinggi motor AC induksi untuk menguji pengendali dan mengembangkan model simulasi motor AC induksi untuk lebih memverifikasi hasil penelitian.

Lokasi kajian penelitian ini dilakukan pada PT. Lamindo Intermultikon. Diagram alur tahapan penelitian adalah dengan studi literature dengan mencari pemodelan matematis dan membuat simulink dari sistem yang ada serta pemrograman dan verifikasi pada simulasi sistem.

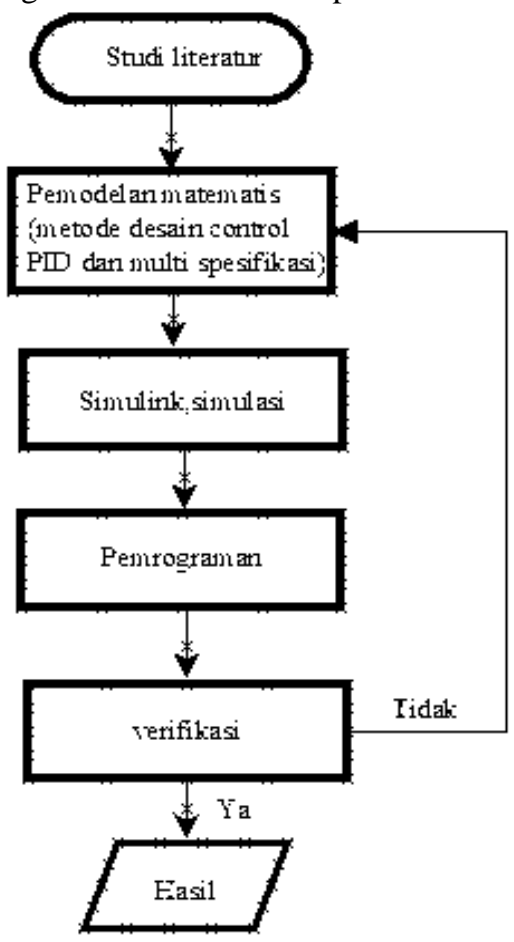

Gambar 2. Diagram alur tahapan penelitian

Metode pengumpulan data yang digunakan dalam penulisan ini menggunakan data dari PT. Lamindo Intermultikon sebagai dasar perhitungan dan simulink menggunakan aplikasi matlab.

Perancangan setting kendali PID loop deskripsi keadaan terdiri dari motor AC induksi, dalam hubungannya vektor fluks kendali inner-loop dan susunan beban inersia melekat motor drive.

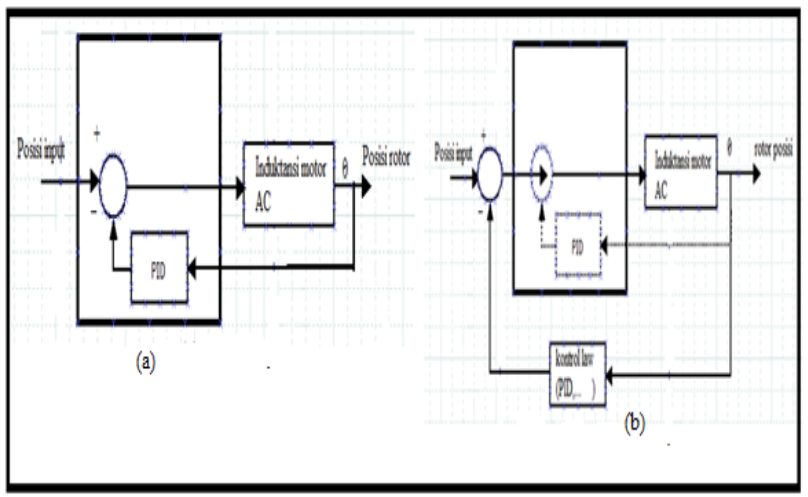

Gambar 3. Pengendali dengan Sistem Kendali PID loop

\section{BAHAN DAN METODE}

Saat ini perangkat lunak yang tersedia digunakan untuk memodelkan dan mensimulasikan motor AC induksi vektor dikendalikan. Sebuah diagram yang mewakili model dinamis motor AC induksi akan diperkenalkan dan struktur program simulasi menggunakan matlab/simulink.

\subsection{Struktur Program}

Sebuah blok simulink diagram lengkap ditunjukkan pada gambar 4.Dalam program simulasi, susunan lengkap persamaan diferensial di d-q koordinat diberikan dalam persamaan (2.4) ke $(2,8)$, diperhitungkan sebagai model dinamis motor AC induksi. Persamaan diferensial ini langsung mengikuti s-fungsi m-file. s-function block, seperti "ind" tertanam dalam I .M. Elec dan "vcontrol" tertanam di vector pengendali dalam gambar 4., menghubungkan m-file ke dalam blok grafis

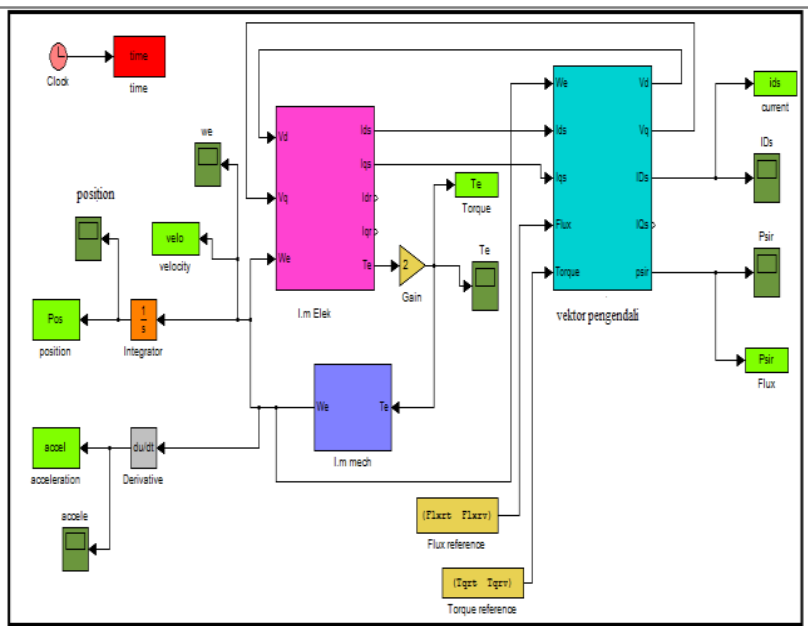

Gambar 4. Vektor dikendalikan Motor AC Induksi Simulink Blok Diagram 
S-fungsi adalah salah satu fungsi matlab untuk memberikan turunan dari semua keadaan dalam model, berdasarkan waktu, input, dan keadaan. Vektor derivatif dikembalikan ke matlab integrasi rutin yang menggunakannya untuk menghitung vektor keadaan baru. Dari vektor-vektor keadaan output dapat dihitung juga mfile kode program dari "ind" dan "vcontrol".

Blok, I.M.Elec, I.M.Mech, dan vektor pengendali digambarkan pada gambar 4., gambar masing-masing dan rincian dijelaskan. Blok I .M. Elec merupakan model dinamik listrik dari motor AC induksi. Di gambar 4.2, masukan 1 dan masukan 2 adalah tegangan input dari pengendali vektor, $V_{d}$ dan Vq. Output 1,2,3 dan 4 adalah arus stator dan arus rotor di stator tetap koordinat d-q, mis, id, IQ, idr dan IQR.

\subsection{Fluks Desain Vektor Pengendali}

Dalam persamaan motor model dinamik termasuk istilah, $\mathrm{Kr}$, yang berkaitan tegangan input diterapkan ke pengendali vektor fluks ke Iq saat,. Ini "Efektif torsi konstan" harus determinan. Untuk menentukan torsi motor efektif konstan, tegangan perintah masukan, \pm $0.5 \mathrm{~V}, \pm \mathrm{IV}$, dan $\pm 2 \mathrm{~V}$, diterapkan untuk motor dengan beban nilai tetap diadakan. Torsi diukur dengan pendekatan ini, dapat dilihat pada tabel 1 .

Tabel 1. Motor Torque Dan Input Tegangan

\begin{tabular}{|l|l|l|l|l|l|l|}
\hline $\begin{array}{l}\text { Tegangan } \\
\text { input(V) }\end{array}$ & -2 & -1 & -0.5 & 0.5 & 1 & 2 \\
\hline $\begin{array}{l}\text { Torque(N- } \\
\mathrm{m})\end{array}$ & - & - & - & $\begin{array}{l}1.10 \\
1\end{array}$ & $\begin{array}{l}2.17 \\
8\end{array}$ & $\begin{array}{l}4.37 \\
4\end{array}$ \\
\hline
\end{tabular}

Dengan data ini, linear kuadrat regresi digunakan untuk menentukan terapan tegangan input (V) Torsi (N-m) torsi efektif konstan sebagai $\mathrm{Kr}=2,194 \mathrm{~N}-\mathrm{mN}$. Hasil regresi ditunjukkan pada gambar 5 .

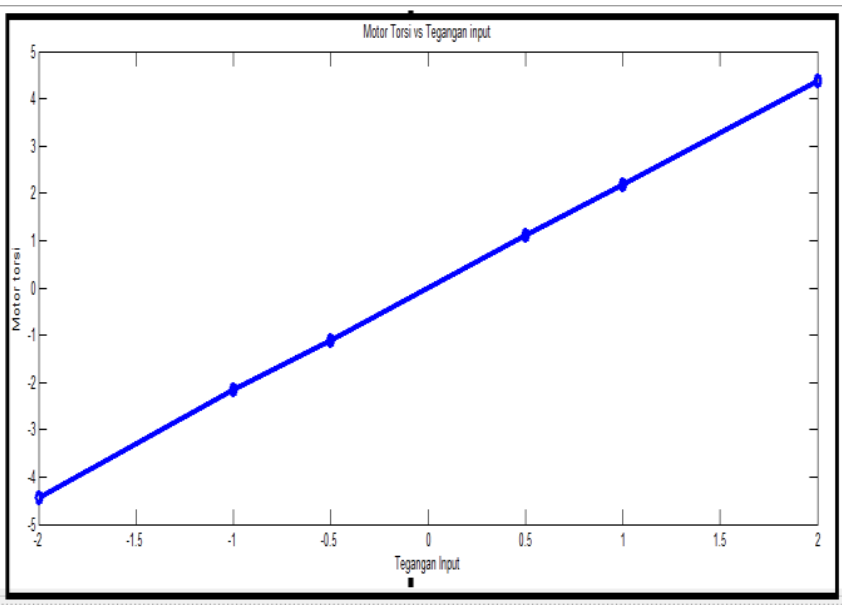

Gambar 5. Motor Torque dan Tegangan Input

\subsection{Estimasi Parameter Simulasi}

Simulasi dilakukan untuk estimasi parameter. Sebuah model yang dikembangkan dimenggunakan matlab/simulink digunakan untuk simulasi. Serangkaian dua puluh semua perintah input acak, $0.296,-0.360,0.362,-0.326,0.151$,
$-0.459,0.211,-0.148,0.433,-0.251$,

$0.504,-0.287,0.343,-0.341,0.428$,

$-0.198,0.406,-0.403,0.191,-0.285$,

Masukan perintah ini digunakan untuk percobaan juga. Perintah masukan tegangan, posisi rotor, kecepatan rotor, dan rotor percepatan simulasi. J dan B bertekad untuk menjadi $0,0623 \mathrm{~kg}-\mathrm{m}^{2}$ dan $0,0103 \mathrm{~kg}-\mathrm{m}^{2} /$ detik masingmasing dalam simulasi.

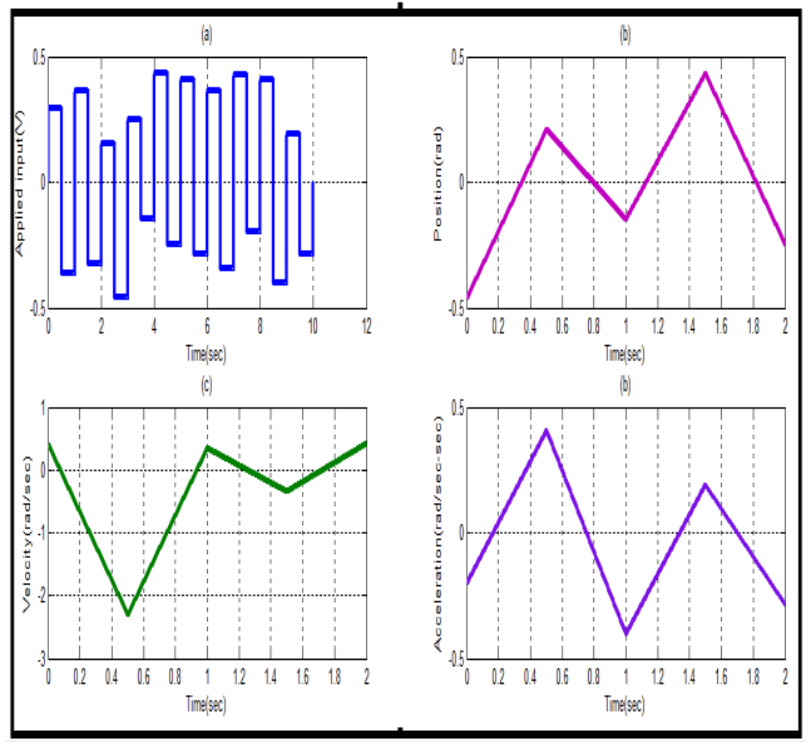

Gambar 6. Simulasi Motor AC Induksi dengan Random Kendali Input

(a) tegangan input (V) (b) posisi rotor (rad)

(c) kecepatan rotor $(\mathrm{rad} / \mathrm{sec})$

(d) rotor percepatan $\left(\mathrm{rad} / \mathrm{sec}^{2}\right)$

\subsection{Model Dinamis Motor AC Induksi}

Mech model simulasi sebagai digambarkan pada gambar 7 di bawah ini.

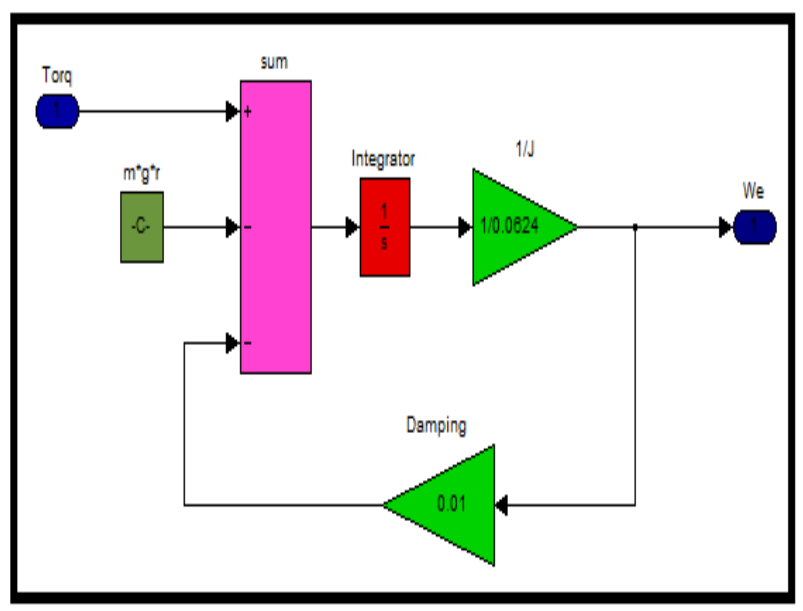

Gambar 7. Blok diagram I.M.Mech dalam model simulasi

Dalam simulasi, PD pengendali digunakan. Dua kelebihan PD dipilih $\mathrm{K}_{\mathrm{P} 1}=7$ Volt $/ \mathrm{rad}, \mathrm{K}_{\mathrm{d} 1}=0,55$ Voltsec/rad dan $\mathrm{K}_{\mathrm{p} 2}=9 \mathrm{Volt} / \mathrm{rad}, \mathrm{K}_{\mathrm{d} 2}=0,5 \mathrm{Volt}-\mathrm{sec} / \mathrm{rad}$. Hasil simulasi ditunjukkan pada tabel 4.2 dan plot yang digambarkan dalam gambar 4.10 
Tabel 2. Hasil Simulasi Kinerja Motor Dengan Pengendali PD

\begin{tabular}{|l|c|c|}
\hline & $\begin{array}{c}\text { Steady } \\
\text { state error } \\
\text { (rad) }\end{array}$ & $\begin{array}{c}\text { Persentase } \\
\text { overshoot } \\
(\%)\end{array}$ \\
\hline $\begin{array}{l}\text { PD kendali 1 (K } \mathrm{K}_{\mathrm{P} 1}=7 \\
\text { Volt/rad, } \mathrm{K}_{\mathrm{d} 1}=0,55\end{array}$ & 0.0121 & 7.38 \\
Volt-sec/rad)
\end{tabular}

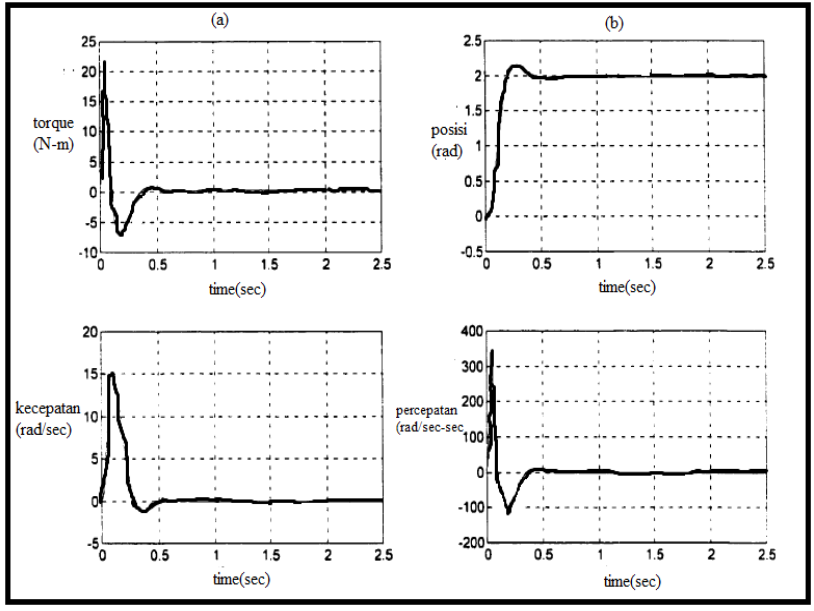

Gambar 8. Hasil Simulasi $K_{P 1}=7$ Volt $/ \operatorname{rad}$ dan $K_{d 1}=$ 0,55 Volt-detik / rad

\subsection{Simulasi Metode Kendali Kombinasi Spesifikasi}

Dalam perangkat lunak untuk melakukan simulasi dari spesifikasi yang bersamaan metode kendali. Pengendali spesifikasi yang bersamaan tertanam dalam program simulasi seperti yang ditunjukkan pada gambar 9 .

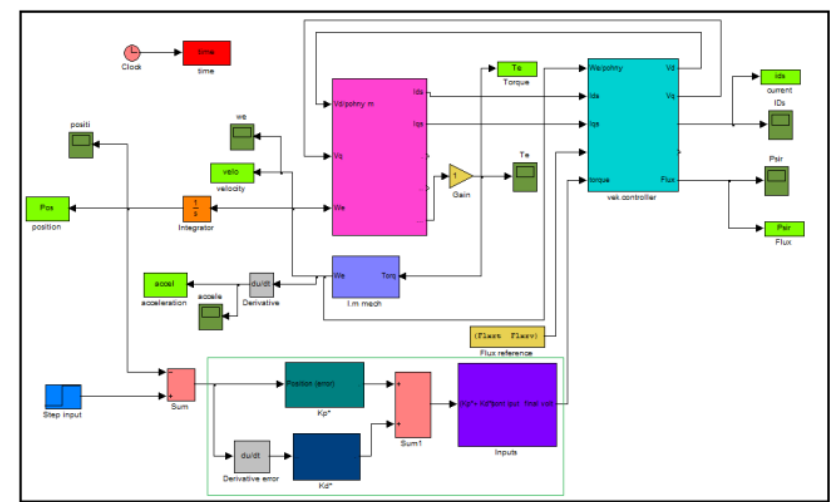

Gambar 9. Vektor kendali motor AC induksi simulink blok diagram dengan spesifikasi pengendali

Dengan program simulasi yang dijelaskan di atas, simulasi induksi kendali posisi motor AC dengan pengendali beberapa spesifikasi secara bersamaan dilakukan. Gambar 4.15 menggambarkan hasil simulasi dari input kendali, posisi, kecepatan, dan tanggapan waktu percepatan motor dan beban inersia.

Pengendali spesifikasi secara bersamaan memberi hasil sebagai berikut:

$$
\begin{aligned}
& \theta_{1(S S . E)}=0.0120 \mathrm{rad}<\alpha_{1}=0.0245 \mathrm{rad} \\
& \theta_{2(O S)}=0 \%<\alpha_{2}=6 \%
\end{aligned}
$$

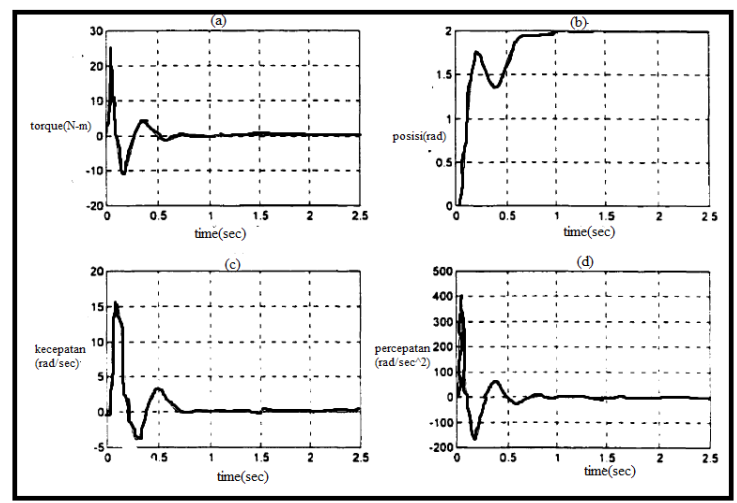

Gambar 10. Motor AC induksi simulasi langkah response pengendali spesifikasi bersamaan

(a) masukan kendali (volt) (b) posisi rotor (rad)

(c) kecepatan rotor $(\mathrm{rad} / \mathrm{sec})(\mathrm{d})$ percepatan rotor $\left(\mathrm{rad} / \mathrm{sec}^{2}\right)$

Dalam bab ini, metode pengendali digunakan untuk derevatif pengendali baru. Sebuah contoh desain numerik diberikan untuk menggambarkan seluruh prosedur untuk metode desain pengendali dengan langkah masukan sebagai masukan referensi error steady state dan persentase overshoot dipilih sebagai beberapa spesifikasi yang bertentangan.

\section{DAFTAR PUSTAKA}

[1] Mitra Hebat Teknik, Motor Listrik Satu Fasa, http://maintenace.wordpress.com/2012/10/25/motorlistrik-ac-satu-fasa.

[2] Dunia Listrik, Motor Listrik AC Satu Fasa, http://dunialistrik.blogspot.com/2012/04/motorlistrik-ac-satu-fasa.html.

[3] Soebagio,"Model mesin AC pada koordinat d-q-n", Materi kuliah Mesin Listrik Lanjut, ITS, 2013

[4] Bimal Kr. Bose," Modern Power Electronics and AC drives", Prentice Hall PTR, 2012.

[5] P. Titinen, P. Pohkalainen, J. Lalu,'The next generation motor control method : Direct torque control (DTC),"EPEJ, vol.5, pp.14-18, Marc.2012.

[6] Nuno M.Silva, Antonio P, Martin, Adriano S.Carvalho,"Torque And Speed Modes imulation of A DTC-Controlled Induction Motor", Proceeding of the 10th Mediterranean Conference on Control and Automation-MED 2002 Lisbon, Portugal, July 2011.

[7] H. Tajima andY. Hori, "Speed sensorless field oriented control of induction motor", IEEE Trans. Ind. Appli., vol. 29, pp. 175-180, Jan./Feb. 2011.

[8] Bambang Purwahyudi, Soebagio dan Mauridhi Hery Purnomo, "Perancangan Neural Network-Genetic Algorithm (NN-GA) Observer Untuk Identifikasi Kecepatan Motor Induksi”, Proceedings SITIA, Jurusan Tek. Elektro ITS, 2 Mei 2011, hal. 436-441. 